Review Article

\title{
Research Progress on Corrosion of Equipment and Materials in Deep-Sea Environment
}

\author{
Sheng Chen $\mathbb{D},{ }^{1,2,3}$ Liping Qiu $\mathbb{D},{ }^{1}$ Shaofang Sun, ${ }^{1}$ Junyi Yang $\mathbb{D},{ }^{2}$ Qinghua Meng, ${ }^{2}$ \\ and Weibo Yang ${ }^{3}$ \\ ${ }^{1}$ School of Chemistry and Chemical Engineering, University of Jinan, Jinan, Shangdong 250000, China \\ ${ }^{2}$ School of Mechanical Engineering, Hangzhou Dianzi University, Hangzhou, Zhejiang 310018, China \\ ${ }^{3}$ Anji ChangHong Chain Manufactring Limited Company, Huzhou, Zhejiang 313300, China
}

Correspondence should be addressed to Liping Qiu; lipingqiu@ujn.edu.cn and Junyi Yang; junyiyang@hdu.edu.cn

Received 25 September 2021; Accepted 5 November 2021; Published 3 December 2021

Academic Editor: Nan Zhang

Copyright ( $\odot 2021$ Sheng Chen et al. This is an open access article distributed under the Creative Commons Attribution License, which permits unrestricted use, distribution, and reproduction in any medium, provided the original work is properly cited.

The deep sea is the frontier of materials research in the 21st century. Owing to the particularity of pressure (15-120 MPa), hydrothermal temperature $\left(90-400^{\circ} \mathrm{C}\right.$ ), and explosive fluid (strong $\mathrm{H}_{2} \mathrm{~S}$ ) in the deep-sea hydrothermal field environment, the research on the corrosion mechanism of service materials in this environment under the coupling action of many harsh factors is almost blank. It has become the bottleneck of equipment and material research and development for China to explore the deep sea. This paper reviews the research progress of corrosion mechanisms of deep-sea environmental materials at home and abroad, and forecasts the research trend and difficulties in this field, especially in the deep-sea hydrothermal field. At the same time, it points out the urgency of the construction of harsh environment materials platform and its relevance to the discipline construction of marine college.

\section{Introduction}

Oceans account for about $71 \%$ of the Earth's surface area and are the largest potential resource base on the planet that has not been fully recognized and utilized by mankind. In addition to offshore oil and gas resources and coastal ores, there are also known metallic mineral resources such as polymetallic nodules, cobalt-rich crusts, and polymetallic sulfides that have commercial exploitation value on the seabed. These minerals are rich in nickel, cobalt, copper, manganese, and gold and silver metals, and the total reserves are tens to thousands of times higher than the corresponding reserves on land. With the increasing demand for metal resources and the exhaustion of land mineral resources, seabed mineral resources will become the replacement resources of mankind in the 21st century. These seabed mineral resources are often referred to as deep-sea mineral resources because they are located at depths of thousands of meters under water. According to the latest statistics in the 2020 InterRidge database (https://www.interridge.org/), more than 700 hydrothermal fields were found on a global scale, including 660 active hydrothermal activity fields and 55 inactive hydrothermal activity areas (Figure 1).

In the deep-sea hydrothermal area (Figure 2), seawater, which penetrates the lithosphere through oceanic crust fissures, is heated by a heat source (surrounding rock or magma chamber) and reacts with the surrounding rock, resulting in changes in the properties of the surrounding rock and seawater itself, and seawater turning into hydrothermal fluid in this process. As it continues to percolate and be heated, the hydrothermal fluids (temperatures of $300-400^{\circ} \mathrm{C}$ and density of $0.7 \mathrm{~g} / \mathrm{cm}^{3}$ ) rise back to the seafloor under buoyant force, forming sulfide-rich hydrothermal fluids that erupt at several meters per second and form ";black chimneys"; (rich in $\mathrm{H}_{2} \mathrm{~S}, \mathrm{H}_{2}, \mathrm{CH}_{4}$, metal sulfides, oxides, metal particles, and so on).

Owing to the high temperature near the vents in the submarine hydrothermal area, a special temperature and pressure field coupled with various extreme factors is formed, with the hydrothermal vent temperature $\left(350-400^{\circ} \mathrm{C}\right)$ at the center, the mineral seawater temperature $\left(50-90^{\circ} \mathrm{C}\right)$ in the nearby area, and seawater temperature 


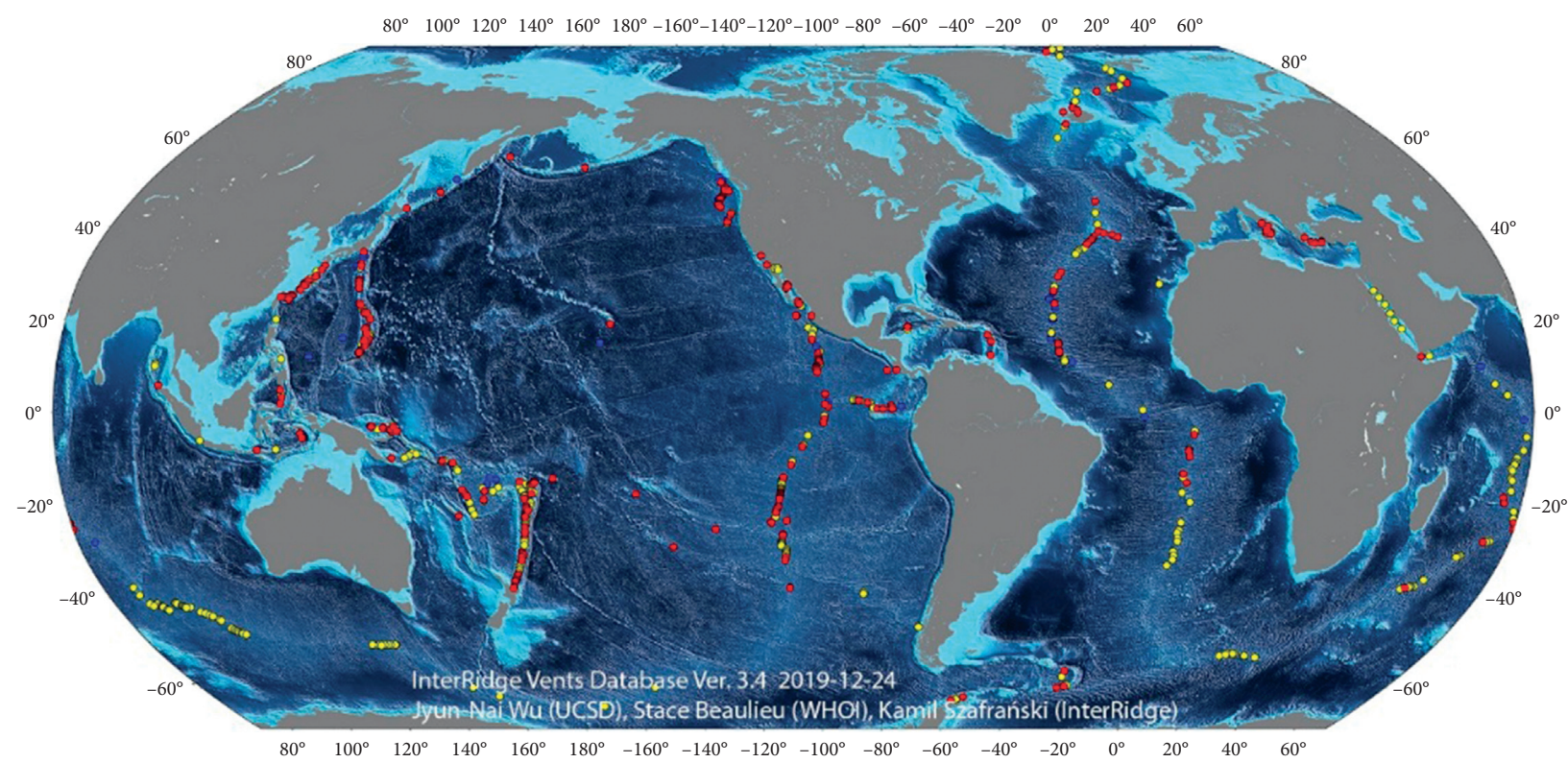

Figure 1: Distribution of hydrothermal activities globally (https://doi.org/10.1594/PANGAEA.917894).

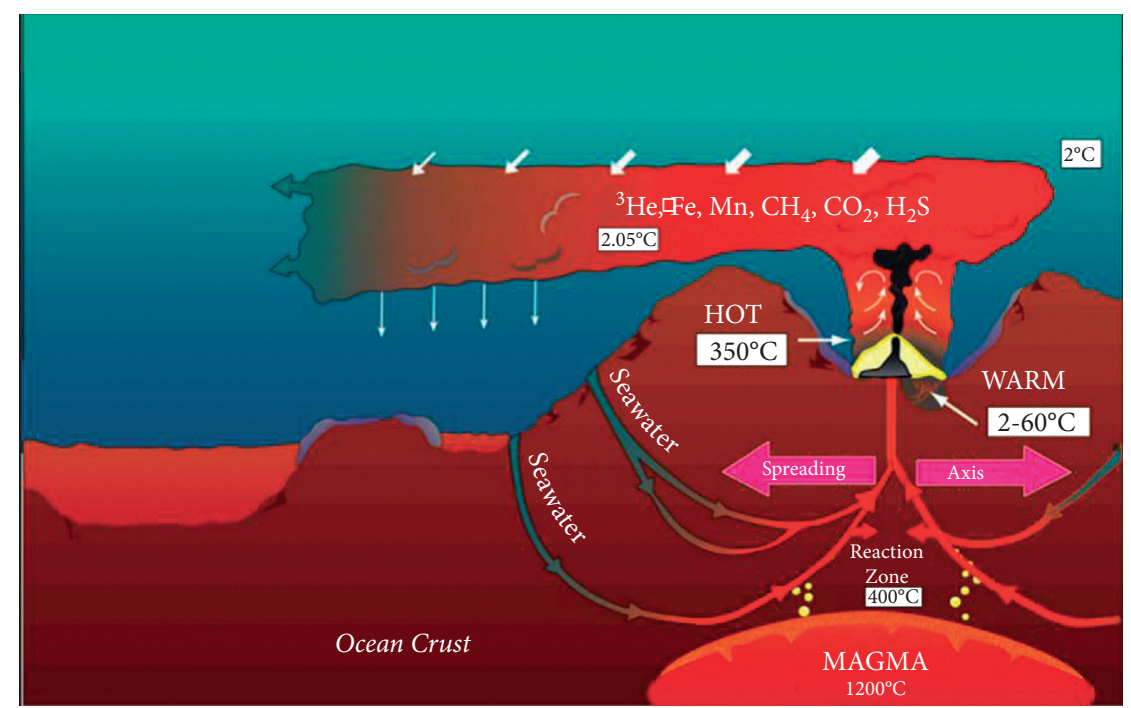

Figure 2: Schematic of hydrothermal activity and hydrothermal plume (figure from Schmidt Ocean Institute).

$\left(0-4^{\circ} \mathrm{C}\right)$ in the outer edge. The in-depth study and exploration of this area will not only provide a new breakthrough direction for potential energy exploitation in the future but also have great theoretical and engineering value for the study of the origin of life and biological evolution. In addition, seafloor hydrothermal activity is a cyclic mechanism of heat and material exchange between the ocean and the seafloor lithosphere [1]. It is a window for human to understand the process of deep earth movement, and its scientific significance and resource potential have become one of the most promising areas for human exploration of nature in the 21 st century.

The outline of the 14th Five-Year Plan points out that China should actively expand the space for the development of marine economy, strengthen the national strategic scientific and technological force, and strengthen the deployment of high-tech in deep space, deep earth, and polar exploration. This is not only because the deep-sea contains rich seabed mineral resources but also with the progress of science and technology and the exhaustion of earth resources, the exploitation and exploration of deep-sea oil and gas, mineral resources, deep-sea engineering construction, and the exploitation and application of deep-sea equipment will become the focus of the development of marine economy in various countries.

However, China's deep-sea equipment manufactured materials for a long time to rely on imports, delaying the pace of China's entry and management of the deep sea. Therefore, it is urgent to accelerate the research on the preparation science and protection technology of materials 
adapted to the deep-sea field in China (especially the extreme environment of the submarine hydrothermal field).

Since the 1960s, material researchers have carried out continuous and effective experimental research in the natural environment corrosion of deep-sea (deep-sea hanging plates) and laboratory simulation corrosion.

\section{Tests in the Deep-Sea Environment}

Starting in the 1960s, some countries have successively carried out material deep-sea environment corrosion aging research to promote the development of their own deep-sea exploration technology, deep-sea resources exploitation technology, space utilization technology, deep-sea environmental protection technology, and equipment manufacturing technology in the deep-sea area, improving its competitiveness in the field of marine technology [2,3].

Between 1962 and 1970, the Civil Engineering Laboratory, Naval Construction Battalion Center, Port Hueneme, California, exposed approximately 20,000 specimens of about 475 different alloys in the Pacific Ocean. These specimens were exposed at the surface and at nominal depths of 2,500 and 6,000 feet for periods of time varying from 123 to 1064 days $[4,5]$. Figure 3 is a schematic diagram of the deep-sea corrosion test device used. The test apparatus, which used a bottom-sitting sample frame, was dropped on the sea floor after reaching the deep-sea test site. During recovery, the anchorage on the seabed was disconnected through acoustic release device, and the connecting rope was brought up to the upper buoy, and finally, the sample frame was lifted. The study found that the effect of depth (seawater pressure) cannot be generalized for different materials. Taking aluminum alloy as an example, the degree of pitting and corrosion cracking in deep-sea environment was much higher than that in shallow sea environment and the corrosion damage was more serious.

At the same time, the United States Lockheed company in 1968-1972 carried out deep-sea tests using seven kinds of coating aluminum alloy and various stainless steel materials; the samples were placed in the Pacific Ocean and the Atlantic Ocean at depths of $1798 \mathrm{~m}$ and $1234 \mathrm{~m}$, respectively. By comparing the corrosion morphology of stainless steel, it is found that the maximum corrosion cracking depth of the two samples is $5.0 \mathrm{~mm}$ and $2.5 \mathrm{~mm}$, respectively. The authors suggest that the oxygen content of the Pacific sample site is lower than that of the Atlantic sample site, which inhibits the passivation of stainless steel and leads to a higher corrosion cracking rate.

In the 1970s, the former Soviet Union carried out deep-sea corrosion tests (Figure 4). On carbon steel, stainless steel, copper, brass, aluminum alloy, and other materials in the Pacific Northwest and the Sargasso Sea [6, 7]. The duration of the experiments was 20,40, and 70 days. Corrosion of stainless steel and aluminum alloys is correlated with temperature and changes appreciably to a depth of $300 \mathrm{~m}$. Below this level (from 300 to $5500 \mathrm{~m}$ ), the corrosion is practically constant. Corrosion of carbon steel depends on the oxygen and silica contents and temperature. India National Institute of Oceanography selected four types of metals (mild steel, brass, aluminum, and stainless steel) for exposure tests during the period November 1987 to November 1988 at depths exceeding $1000 \mathrm{~m}$ in the Arabian Sea, to assess their behavior with respect to corrosion. The results indicated an increase of the corrosion rate of mild steel and brass with increased depth, whereas in the case of stainless steel and aluminum, the corrosion rate decreased with increased depth. This difference in behavior with respect to depth could be attributed to the characteristic way that metals and alloys react with the dissolved oxygen present in the water column $[8,9]$. In addition, it was also pointed out that although macroscopic biocontamination was minimal in deep-sea conditions, the growth of microbial films on the sample surface and the corrosion induced by microorganisms could not be ignored, although the inhibition effect of high pressure in the deep sea on the growth of many microbial communities was limited [10].

In recent years, the latest advances in deep-sea corrosion testing have come from European research teams (Figure 5). This study aims to investigate the deep-sea environment effects on the corrosion of $\mathrm{Al}, \mathrm{Fe}$, and $\mathrm{Cu}$ alloys, employed in the $\mathrm{KM}_{3} \mathrm{NeT}$ project, a deep-sea infrastructure designed to host a neutrino telescope [11-14]. Alloys commonly used in seawater, as well as less widely employed materials, were studied. Samples were immersed at the NEMO site (located off Capo Passero, Italy; $3365 \mathrm{~m}$ depth) for consecutive time periods of 6,12 , and 18 months. A representative set of samples was recovered, and laboratory tests were performed to evaluate the type and degree of corrosion attack. Stainless steel reported the best performance in terms of the weight loss, corrosion rate, and corrosion morphology. However, also Al 5093 and $\mathrm{Al} 6082$ performed satisfactorily in terms of the weight loss and corrosion rate. This prescreening will be partially employed in selecting building materials for the KM3NeT structure. Some studies have pointed out [11] that deep-sea conditions will also change the corrosion products of aluminum alloys. The corrosion products of 6000 series aluminum alloy are $\mathrm{Al}(\mathrm{OH})_{3}$ in the shallow seawater environment at 1 atmosphere pressure, while the corrosion products in the deep-sea environment are mainly aluminite $\left(\mathrm{Al}_{2} \mathrm{O}_{3} \cdot \mathrm{H}_{2} \mathrm{O}\right)$.

In 2008, CSIC 725 Research Institute took the lead in carrying out large-scale aging test of material corrosion in deep-sea natural environment in China, successfully breaking through several key technologies such as lowpower long-term self-sustaining design of deep-sea test devices, simulation, and analysis of underwater stress state of large depth deep-sea test device, and in-situ corrosion detection of deep-sea $[15,16]$. The deep-sea environmental tests at different depths have been carried out in the South China Sea, and more than 13000 deep-sea corrosion data of 9 categories and more than 40 kinds of different materials and different periods have been accumulated. The first deep-sea corrosion aging database of materials in China was established. The environmental factors such as sea temperature, salinity, dissolved oxygen, and current velocity in the test area were measured and collected, and the relationship between material corrosion and environmental factors was discussed, which promoted the systematic study of material properties in the deep-sea environment in China $[17,18]$. 


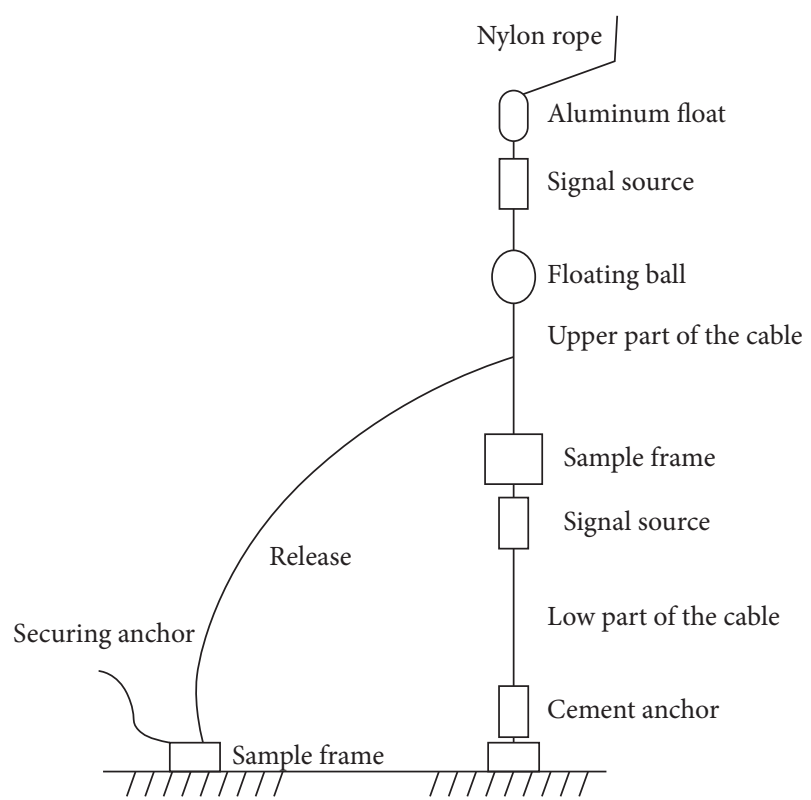

FIGURE 3: Seated bottom type deep-sea corrosion test device (figure from [5].

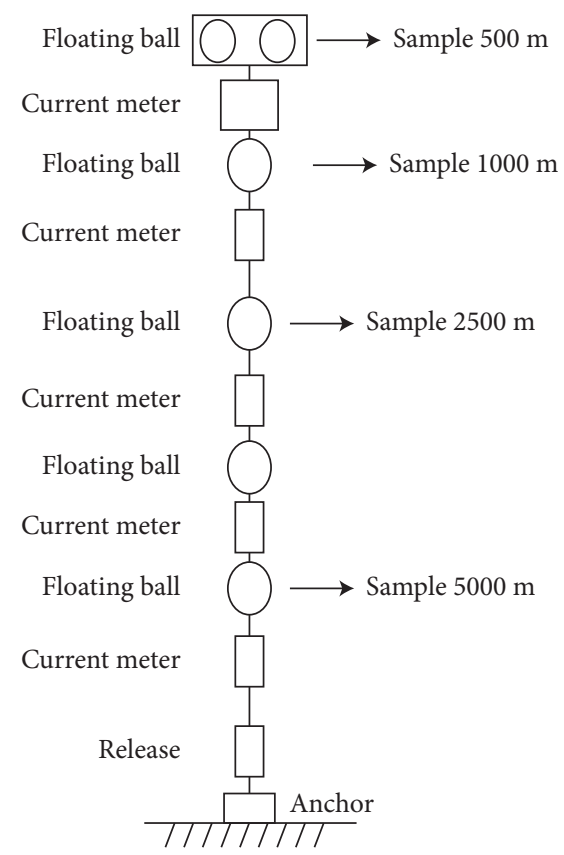

FIGURE 4: Bunch-style testing system (figure from [5]).

With the manned submersible "Jiaolong" and the semisubmersible deep-water drilling platform ";Haiyang Shiyou 981", which were designed and integrated by our country, reaching the depth of $7000 \mathrm{~m}$ and entering the South China Sea to carry out deep-water operations, the problem of erosion of deep-sea equipment in deeper waters and more demanding environment has become increasingly prominent. The harshness of the deep-water environment results in severe corrosion hazards [4, 19-21], which may even become the technological bottleneck for the development of deep-sea resources, utilization of deep-sea space, and construction of deep-sea engineering, thus affecting the smooth research and development of China's Marine economy and deep-sea equipment.

It is also pointed out [22] that under deep-sea conditions, stainless steel components will be subjected to great static pressure, stress corrosion sensitivity will sharply increase, and mechanical properties will continue to deteriorate, which will seriously threaten the service safety of deep-sea structures and equipment. The corrosion properties of titanium alloy in deep-sea environment were studied and tested, and the results show that it has excellent corrosion resistance and pitting resistance, and almost no corrosion occurs at low temperature in deep sea.

\section{Laboratory Simulation Corrosion}

Although the results of deep-sea sling-plate test are real and direct, the experiment cost is expensive, the experiment cycle is long, and the continuous reliability of the experiment is difficult to guarantee because of the harsh deep-sea environment conditions. Therefore, it is increasingly urgent to simulate deep-sea environment conditions and carry out laboratory corrosion experiments. The simulated accelerated corrosion method in the laboratory is to study the main factors and laws of material corrosion by chemical or electrochemical accelerated methods by simulating the deepsea environment using small samples and an artificial seawater medium.

Pohjanne studied the corrosion behavior of aluminummagnesium alloy 5083-H116, aluminum-silicon magnesium alloy 6082-T6, and aluminum-zinc magnesium alloy 7020T5 in a simulated deep-sea environment by a laboratory experiment [23]. The test results indicated that the pitting corrosion resistance of aluminum alloys decreased as the depth increased, but the effect depended much on the alloy. The deterioration in corrosion resistance is caused by the changes in the chemical composition of the sea water and the hydrostatic pressure.

Norway and India have carried out electrochemical measurements of deep-sea corrosion of metals, but their methods and emphases are different. In India, the exposure test was carried out in the Indian Ocean at a depth of $5000 \mathrm{~m}$, while seawater was collected from $500 \mathrm{~m}$ to $1200 \mathrm{~m}$ deep and sent to the laboratory as a medium for polarization detection of steel samples. Although the test results obtained cannot be completely reliable but, as a relative comparison, are feasible. During 1982-1984, the Norwegian Ship Research Institute conducted deep-sea cathodic protection measurements of materials at various sites in the North Norwegian Sea, ranging from $400 \mathrm{~m}$ to $1200 \mathrm{~m}$, and obtained the protection current density of steel at different depths off Norway. Researchers developed a deep-sea corrosion potential and galvanic current multichannel test devices for metal materials (Figure 6), which can monitor the corrosion process of dozens of metal materials in situ, providing strong technical support for the study on deep-sea corrosion mechanisms of metal materials, as well as the specific material compatibility application in deep-sea environment [24]. 


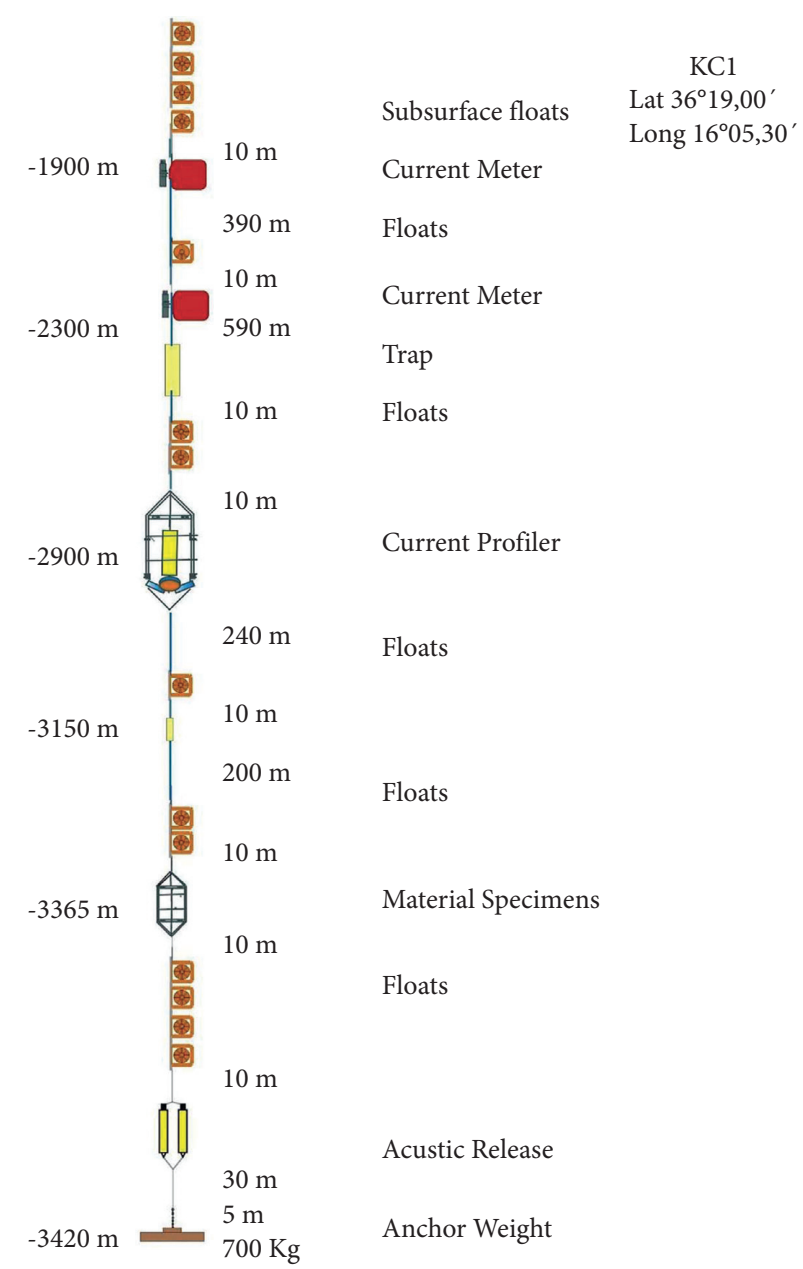

FIGURE 5: Outline of the KCL mooring line (from [11] located at the NEMO site).

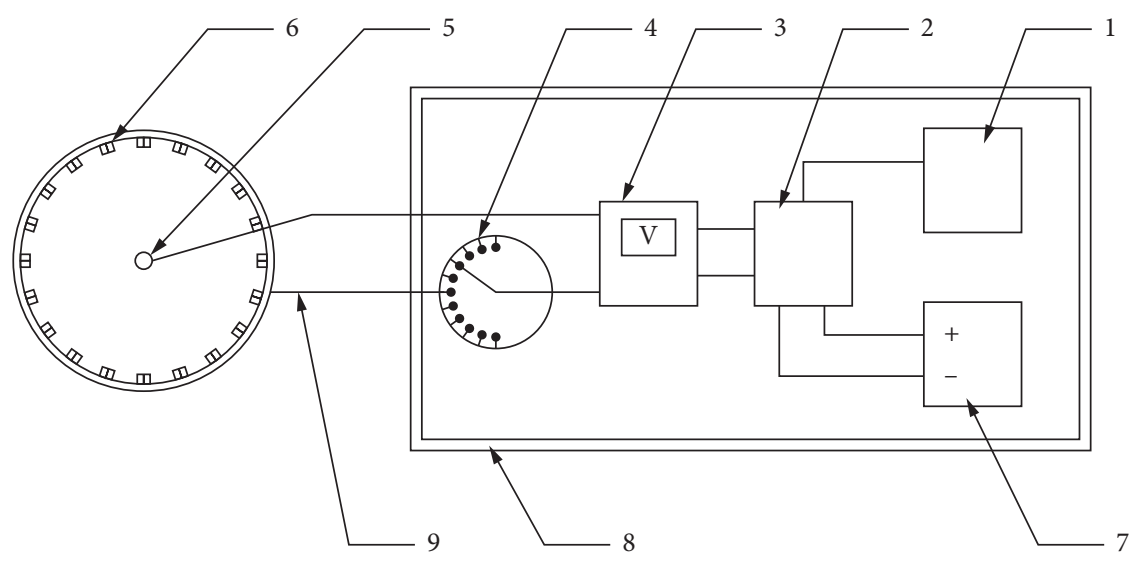

FIGURE 6: Schematic diagram of assembly structure principle of invention device (from [24]. 1-Data Storge, 2- General control device, 3potentiometer, 4- transverter, 5- reference electrode, 6- under test sample, 7-battery, 8- pressure hull, 9-pressure resistant multicore wire.)

The China University of Petroleum designed a water-tight electronic chamber (Figure 7) that can conduct various corrosion electrochemical online monitoring operations in a water depth of $300 \mathrm{~m}$ [25]. CSIC 725 Research Institute, the University of Science and Technology, the Beijing Ocean University of China, the Institute of Metals, the Chinese Academy of Sciences, and other domestic research institutes have carried out fruitful research work and obtained a lot of important data in the field of deep-sea materials laboratory corrosion $[16,26]$. Yuan focused on the main characteristics of the marine environment, which include temperature, dissolved oxygen, and static and dynamic load; the effects on the electrochemical 


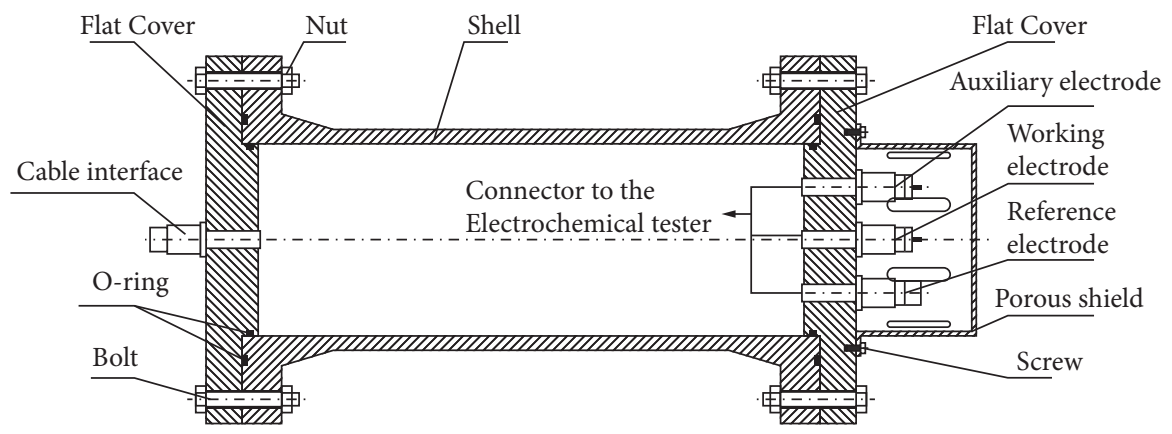

Figure 7: Shell structure of the watertight electronic cabin (figure from [25].

corrosion behavior and hydrogen embrittlement under cathodic protection of $\mathrm{X} 80$ pipeline steel in $\mathrm{pH}=7.7 \pm 0.2$, $3.5 \mathrm{wt} . \% \mathrm{Na} \mathrm{Cl}$ simulated seawater were studied, and the influence law and mechanism of various marine environmental factors were discussed for providing basic data and theoretical guidance to the application and protection of X80 pipeline steel in marine engineering [27]. At present, most of the research focuses on the following aspects:

3.1. Simulation Prediction. Researchers studied the influence of environmental factors such as the $\mathrm{pH}$ value and calcium and magnesium ion deposition on the corrosion behavior of materials in the deep seas $[28,29]$. On this basis, a database and simulation prediction model related to seawater corrosion parameters and corrosion velocity are established. Hou et al. predicted the corrosion velocity of A3 steel at different depths in the South China Sea using the function expression between corrosion velocity of A3 steel and marine environmental parameters based on systematically summarizing the characteristics and variation rules of environmental factors of deep-sea corrosion such as dissolved oxygen, temperature, and salinity.

Jia Wang and his team from the Ocean University of China studied the corrosion behavior of five kinds of marine engineering steels above $5000 \mathrm{~m}$ deep-sea environment using electrochemistry, artificial neural network, and database methods [30]. The results showed that temperature, dissolved oxygen, salinity, and the $\mathrm{pH}$ value were the main factors which affect the corrosion behavior of the five steels in seawater. Two databases, MCM-CORRDB03 and MCMGOCEANDB03, were established and used to predict the corrosion rate of related steels in different deep-sea environments. It is pointed out that the deep-sea corrosion behavior of different metal materials is very different, and the main environmental factors are different. It was confirmed that the minimum corrosion rate of the behavior was appeared at a depth of 5000 meters, and the content of dissolved oxygen has the greatest effect on the corrosion behavior of the steels in deep ocean.

3.2. Stress Corrosion. Most of the alloy in the deep-sea environment is not sensitive to stress corrosion; however, the deep-sea environment determines the must usage of the highstrength alloy with high stress corrosion sensitivity; therefore, the role of hydrogen in the deep-sea stress corrosion mechanism research should not be ignored. High hydrostatic pressure by influencing the process of stripping, absorption, and penetration may change the material stress corrosion sensitivity. The crack growth rate of stress corrosion failure is generally between $10^{-6}$ and $10^{-3} \mathrm{~mm} \mathrm{~s}^{-1}$, which is much higher than the corrosion rate without stress. Stress corrosion cracking usually has no obvious symptoms, but it often results in catastrophic results [31]. At present, only a few countries in the world have carried out deep-sea environmental corrosion tests of materials. The United States (Hueneme Port test station), the former Soviet Union, Japan (Kitakyushu test site and Beppu test site), the United Kingdom, and other countries began to conduct deep-sea environmental corrosion test studies of materials in the 1960s, followed by Norway, India, and other countries [4].

3.3. Temperature. Temperature can not only directly affect the corrosion behavior of materials but also intensify (coupling) the influence of other corrosion factors. The increase of temperature will accelerate the reaction rate of cathodic and anodic processes, increase the diffusion rate of oxygen, increase the conductivity of seawater, and promote the corrosion process. Research shows that when the temperature is around $23^{\circ} \mathrm{C}$, the corrosion rate is the largest, while the deep ocean water temperature is lower than $23^{\circ} \mathrm{C}$; the corrosion rate for carbon steel and low alloy steel will decline with the increase of depth. The study from Yuan [27] provided more detailed information about the effect of temperature. The promoting effect of temperature in corrosion was realized by accelerating anodic dissolution. The cathode process was closely related to the concentration of dissolved oxygen, and the Evans diagram was obtained (Figure 8). With the decrease of the concentration of dissolved oxygen, the corrosion rate decreased significantly. However, in the deep-sea environment, high-temperature factors (such as seafloor hydrothermal area) on the material of the coupling corrosion mechanism exploration are almost blank [30].

3.4. Velocity of Sea Water. Seawater flow can scour the corrosion products, weaken the blocking effect of corrosion product deposition on the corrosion reaction, and accelerate the corrosion reaction. Corrosion of deep-sea equipment is usually much less affected by velocity in the deep sea than that at the surface $[4,32]$. 


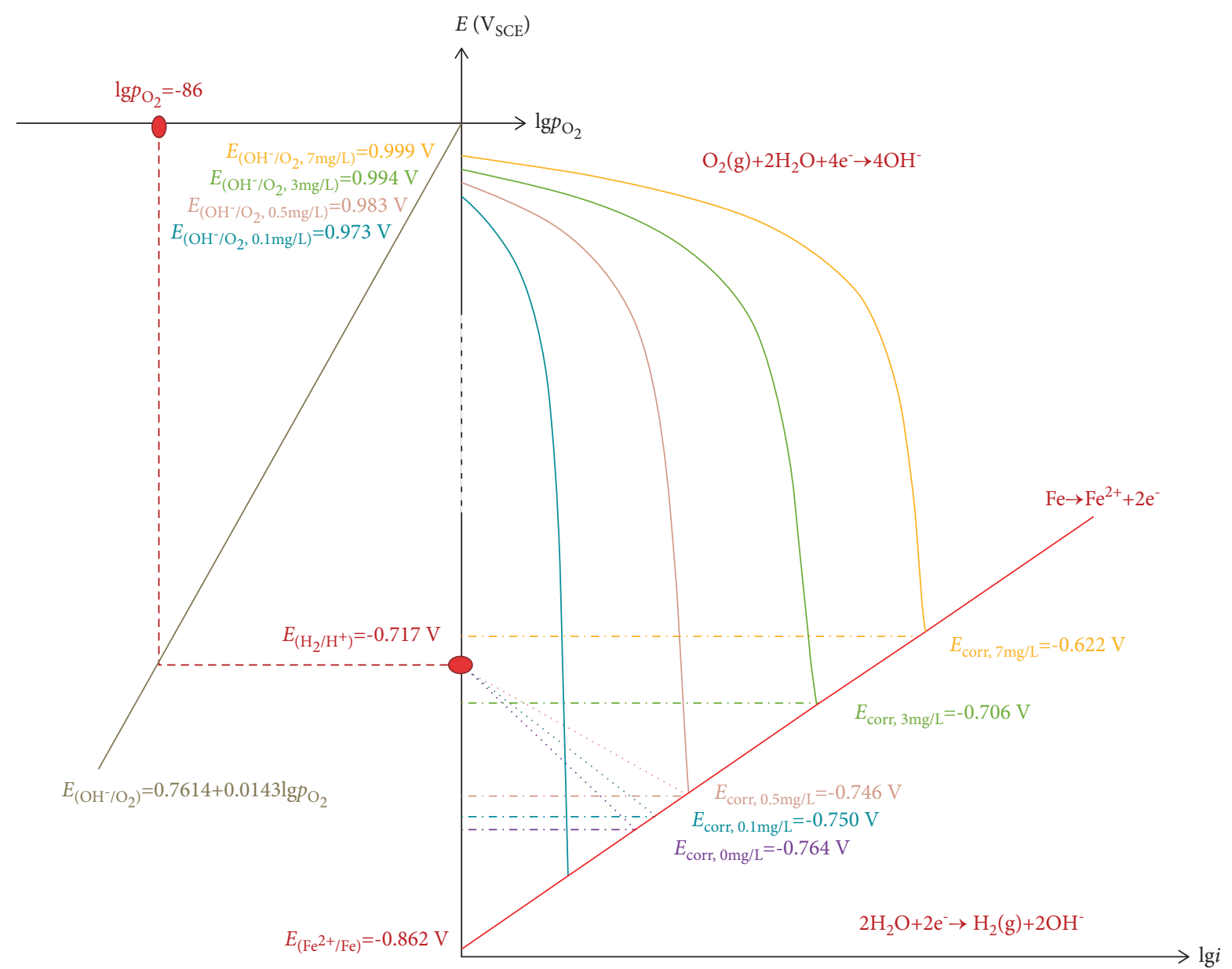

Figure 8: Evans diagram for the corrosion of X80 pipeline steel in the $3.5 \% \mathrm{NaCl}$ solution with different dissolved oxygen concentrations (from [27].)

Tang et al. compared the corrosion rates of Q235 carbon structural steel (A3 steel) in static and flowing seawater by indoor and deep-sea weight loss tests, and tested the corrosion rates of Q235 carbon structural steel (A3 steel) by the potentiodynamic method, as well as the environmental parameters in seawater with different flow rates [33].The results show that the seawater flow can accelerate the corrosion rate of Q235 carbon structural steel in seawater, especially in the initial stage of corrosion.

Researchers studied the corrosion behavior of five kinds of aluminum alloys in flowing seawater [34]. The results show that aluminum alloys are more resistant to corrosion than carbon steel and copper, especially al-Mg-Al alloys and al-Mg-Mn alloys. Because Al-Cu and Al- $\mathrm{Zn}-\mathrm{Mg}$ alloys have obvious peeling corrosion sensitivity in flowing seawater, they should not be used in flowing seawater environment. These experimental results are only suitable for shallow sea experiments under atmospheric environment or low pressure. In addition, eddy-induced vibration is easily caused by ocean current, which causes fatigue damage to slender structural parts such as columns, pile legs, and submarine pipelines, affecting the safety of marine engineering structures [31].
3.5. Pitting. Pitting is the phenomenon of corrosion holes with deep development in local areas of the metal surface and no corrosion or slight corrosion in other areas. The application of cyclic stress can promote pitting initiation. SEM observation results show that the increase of hydrostatic pressure increases the metastable pitting and increases the sensitivity of average corrosion performance of $\mathrm{Ni}-\mathrm{Cr}$ Mo-V steel [2, 35, 36].

As mentioned above, decades of systematic exploration laid the experimental and theoretical foundation for the subsequent in-depth research and development of deep-sea materials. However, owing to the lack of research platforms and means and the low degree of perfection, especially the field of research starts late in China, it left a lot to be explored and perfected.

\section{Development Trends and Difficulties}

4.1. Shortcomings of Deep-sea Material Corrosion Test Research. Owing to the limitation of depth and real-time detection in deep-sea environment, previous deep-sea corrosion tests were only carried out in the deep-sea environment of about $6000 \mathrm{~m}$ for a variety of metal materials, 
while the data of material corrosion in the deeper sea are scattered and lack of systematic.

During the test of corrosion and aging of materials (bolt) in the deep natural environment, the domestic and foreign experts measured and collected the environment factors such as seawater temperature, salinity, dissolved oxygen, current velocity, and probes into the relationship between the environmental factors and the material corrosion. However, in experimental design, pressure (depth) is usually taken as a variable factor, while other ocean factors are basically considered constant or with small variation range, and there is a lack of effective means to systematically test and detect the corrosion of materials under the coupling effect of multiple factors in deeper waters and more demanding environments. Owing to the single influencing factor, or the lack of multiple factors, coupling and alternating to exert a significant impact on material corrosion (such as seawater flow under deep pressure and temperature rise influence on material corrosion law and superimposed effect) results detection; therefore, it is difficult to provide an accurate theoretical description and guidance for material design and equipment protection in more complex and harsh environment (such as hydrothermal field environment) in deep sea.

Given the limitations of natural deep-sea corrosion experiments, although experts developed a multichannel device to test the potential and galvanic current of metal materials during corrosion in the deep-sea environment, designing and developing one electrochemical test device, which could tolerate deeper water pressure, is resistant to outside interference, and could integrate with electrochemical data acquisition, storage, and remote (wireless) transmission, is still difficult, Therefore, the corrosion mechanism of deep-sea environmental materials remains to be further studied.

In addition, the previous theoretical research and discussion of corrosion are mostly focused on the surface protection technology of materials, while the research on the design theory and preparation science of materials is less, resulting in the long-term lag in the research and development of key materials in this field and becoming the bottleneck of China's entry into the deep sea and exploration of the deep sea.

4.2. Experimental Research Trend of Deep-Sea Material Corrosion. The research on the corrosion mechanism of deep-sea materials is the basis of the research and development of deep-sea equipment and materials. Only by conducting an overall and comprehensive research on the corrosion mechanism in the deep-sea environment can the targeted design, protection, and selection of equipment and materials be carried out according to the deep-sea service environment. Based on this, further research on the corrosion of environmental materials in the deeper sea is carried out to complement the corrosion tests in the deepsea area. It will be the direction and trend of the research and development of the corrosion mechanism of deep-sea materials and their adaptive materials in the future to design and establish the environment simulation corrosion platform of deep-sea hydrothermal zone and carry out the corrosion mechanism research of materials in this field.

To realize the deep sea, especially near hydrothermal area, the coupling corrosion environment influence the mechanism of the key factors in the process of repeatability test, an urgent need to design and manufacture of deep-sea environment experiment simulator, with in situ observation and real-time measurement on the basis of the following functions: (1) safe injection or controllable generation of the harmful gases under a high-pressure and high-temperature environment; (2) in the high-pressure and harmful gas test environment, ensure the smooth matching of pressure in the heating process; (3) in the test environment, material corrosion information is collected smoothly and has good repeatability.

To select and design high-strength metal materials for deep-sea use, metal materials (such as precipitated hardened stainless steel) that are expected to be suitable for such harsh environments (such as near the hydrothermal zone) should be selected for three types of experiments. That is, no load, elastic load, and plastic deformation of the deep-sea hydrothermal zone environmental coupling corrosion experiment.

On this basis, the multifactor coupling corrosion mechanism of high-strength metal materials is explored, which will promote the design and preparation of deep-sea extreme environment simulation devices and carry out innovative experimental research.

\subsubsection{Multifactor Coupling Corrosion In the Deep-sea} Environment. In the deep-sea hydrothermal area environment (Pressure: 15-120 MPa, temperature of hydrothermal vent: $90-400^{\circ} \mathrm{C}$ ), multisystem, multifactor (the strong $\mathrm{H}_{2} \mathrm{~S}$ and other harmful gases, intense upwelling of ocean currents (seafloor storm) caused by temperature changes) interweave and superimpose each other and act together on the service equipment and materials in this environment. The strong coupling effect may magnify the influence degree of a factor by several or tens of times.

\subsubsection{Design of the Total Element Deep-Sea Simulation} Experiment Device. The designed and prepared deep-sea extreme environment corrosion simulation device should meet the full-depth pressure $(120 \mathrm{MPa})$ condition within the known deepest ocean. The maximum operating temperature of $430^{\circ} \mathrm{C}$ can cover all the found hydrothermal zones and the surrounding ambient temperature. Flexible safe injection and extraction function of gas, microorganisms, corrosive gas, and liquids can ensure the implementation and detection of multifactor coupling corrosion process. The design of a continuous and precisely controlled agitation system in the range of 0-2 $000 \mathrm{r} / \mathrm{min}$ will simulate the state of deep-sea current inrush to simulate the seabed inrush velocity in the range of $0-15 \mathrm{~m} / \mathrm{s}$. The simulation device with the aforementioned design conditions will be able to simulate the harshest environment of the deep sea to the greatest extent. 
4.2.3. Fill the Blank Of the Deep-Sea Integral Corrosion Test. The experiment of material corrosion in deep-sea hydrothermal zone will improve the overall corrosion mechanism of deep-sea materials and fill in the blank of material corrosion mechanism in this area. The structure, composition, morphology, and distribution of each component phase or microstructure in the microstructure of materials subjected to multifactor coupling corrosion were studied. The mechanochemical effect mechanism of materials in an extremely harsh (near hydrothermal field) environment is revealed at macro and phase scales. In the future, it will be one of the important innovative research directions for the cross-penetration of deep-sea engineering and material engineering to combine the corrosion mechanism of materials with the change of microstructure and adaptive design of materials, to select, protect, and design equipment and materials for service in the extremely harsh deep-sea corrosive environment.

\section{The Urgency of R\&D Platform and Team Building}

5.1. Support of National Development Strategy. Marine harsh environment refers to the extreme environment in the deep sea, harsh ocean conditions in the far sea, the alternation of temperature difference, polar ice water, deep cold, and so on, which is summarized as the ";four poles"; of the ocean. With the expansion of national resources exploration and drilling to the sea areas with more complex geological conditions and physical environment, the equipment and materials in service will certainly suffer from wear and corrosion in the harsh and extreme environment. However, owing to the blank material test platform, it is difficult to organize a special research team, which makes it impossible to start the research on the erosion mechanism of equipment and materials in service in extreme environment, especially in the South China Sea, deep sea, open sea, polar, and other harsh environments. As a result, the selection of engineering materials, research and development, and large-scale application greatly lag the strong expectation of the demands in this field and become the bottleneck of national energy drilling and ocean engineering development.

In the 21st century, mankind has entered a period of large-scale exploitation and utilization of the oceans. Marine undertakings are related to the survival and development of the nation and the rise and fall of the country. Zhejiang is not only a large province of marine resources, but also a strong province of marine economy. During the 13th Five-Year Plan period, the provincial Party Committee and government actively promoted the development of marine economy, and formed a good pattern of marine economic development led by the construction of world-class marine ports, driven by the construction of a modern marine industrial system, and supported by strengthening the construction of marine science and education and ecological civilization. To further promote the province's marine economy comprehensive strength and modernization level, to better support the construction of a powerful province of marine, Zhejiang province specially formulates 14 th five-year plan of Marine economy development, attaches importance to and promotes breakthroughs in key technologies, carries out "double sharp double collar" plan. Centering on marine resources, disaster prevention and mitigation, marine new materials, marine engineering equipment, and high-tech ships, scientific research projects are set up in provincial key research and development programs to overcome several key technologies, fully highlighting the economic, ecological, and sustainable capabilities of marine resources development and engineering construction. However, the harsh and complex deep-sea environment seriously restricts and threatens the exploitation of resources and the service safety of marine equipment.

Due to historical reasons, the research on corrosion and protection of marine equipment and materials serving in the harsh marine environment in China is still not thorough, which is very inconsistent with the national strategy and development plan. Therefore, around the regional economic and technological development, strategic target for deep harsh environment in the process of the development of key materials preparation and erosion protection of scientific problems and the corresponding experimental platform construction and exploration, to research and develop the basic theory and form new series which is suitable for the demanding deep and complicated environment adaptability of materials and erosion protection technology. It is of great significance for the development of national strategy and location to build a first-class material research and development and erosion protection team to serve the national overall marine strategy, resource development, and national defense construction and to promote the transformation of China from a major maritime country to a maritime power and Zhejiang from a large province of marine resources to a strong province of marine economy.

The ways to break the bottleneck of service equipment and material corrosion in harsh marine environment are as follows: (1) reasonable material selection and key material development on the basis of the accumulation of a large amount of material environmental corrosion data and research of regularity; (2) establish safety evaluation and life prediction methods for materials in service in harsh environments (deep-sea hydrothermal zone, high humidity and heat in south China Sea, polar cold, etc.); (3) provide reasonable and effective protection technology. The key to link these three aspects is the rapid establishment of a research platform for the corrosion regularity and mechanism of marine engineering materials under harsh environments.

Timely proposed establishment of marine harsh environment materials research and development and protection platform, which is of great significance to improve the layout of Zhejiang Provincial Key laboratory of Marine materials and scientific research and discipline construction of related institutes.

The construction of the platform and the research on the mechanism of material corrosion will highlight the interdisciplinary and integration of various disciplines (life science, environmental science, chemistry and chemical engineering, marine geology, marine physics, etc.). The construction of the platform and the research on the 
mechanism of material corrosion will highlight the interdisciplinary and integration of various disciplines (life science, environmental science, chemistry and chemical engineering, marine geology, marine physics, etc.). The establishment of a key laboratory for the research and development of material erosion mechanisms and protection technology in marine extreme environment is the first in China, which will highlight the creativity of the research field. It will benefit Zhejiang province to lead the fierce competition trend of international energy exploitation to march into the deep sea and support the strategy of strong ocean province, to promote the strategic needs of national and provincial marine science and technology development, and to fill the blank of Zhejiang Province's harsh marine environment materials basic research and adaptive materials research platform.

\subsection{Platform and Talent Team Construction. Zhejiang} province attaches great importance to the development of marine strategy. Aiming at the development of science and technology in the field of marine, it has carried out a relevant advanced layout of the key laboratory of Marine science and technology. Related institutes, respectively, set up MNR Key Laboratory of Submarine Geoscience, State Laboratory of Satellite Ocean Environment Dynamics (SOED), Ocean Engineering Survey, Design and Research Institute, Polar Deep-Sea Technology Institute, Key Laboratory of Marine materials and Related technologies, CAS, Zhejiang Provincial Key Laboratory of Marine Geotechnical Engineering and Materials, Zhejiang Greater Bay Area (Wisdom Ocean) Innovation and Development Center, Zhejiang Provincial Science and technology innovation Service platform for sea trial, and so on. Especially in the Key Laboratory of Marine materials and Related technologies, CAS, guided by the national Marine strategy and regional Marine industry needs, focuses on basic research, process technology integration, and engineering application of marine new materials; studies the interaction between materials and the marine environment; targets on three major marine material damage problems, such as electrochemical coupling corrosion, biological fouling and mechanical-chemical interaction wear; and accelerates the core collaborative capability research and development of failure mechanism and application technology, gradually improving the design and preparation of new marine materials, new coupling damage mechanism, and engineering technology innovation system, becoming a bridge and link for industrial transformation and national defense application of marine new materials.

\subsection{The Latest Research Direction of Marine Service Materials in Harsh Environment}

5.3.1. Erosion Interface and Erosion Process Dynamics. According to the seawater environment in deep-sea hydrothermal area, we systematically study the corrosion failure behavior of metal materials (nickel base alloy, copper alloy material), nonmetallic ceramic materials, and composite materials in the mechanical and chemical interaction of high temperature, high pressure, and strong corrosive medium seawater. On this basis, aiming at the characteristics of the deep-sea energy mining equipment, such as serious erosion phenomenon, short service life, low safety, and high cost, by adjusting the microcomposition and surface protection of materials, improved the corrosion resistance, and mechanical properties of materials, enhancing the safety of deep-sea energy exploitation.

\subsubsection{Microbial Adhesion Corrosion Process and Protection} Technology. Biological fouling is a prominent marine material damage problem faced by marine engineering and equipment. Reveal the interface binding mechanism of marine fouling organisms attached to the surface of materials (especially the lush biological environment in the high humidity and heat of the South China Sea and the submarine hydrothermal zone) and develop antifouling bare engineering materials or adaptive protective materials, which lay a good foundation for solving the problem of biological fouling on the surface of engineering equipment materials in the high humidity and heat (and deep-sea hydrothermal area) sea area in the South China Sea. Previous research is limited to the interface and surface formed between inanimate materials, while the interface and surface formed between the marine material and microbial activity is half of life, and half of the unique compound interface, with the common organizational structure characteristics of the composite interface, and the unique structural characteristics of dynamic development and both "active" biochemical reaction, therefore, making the interface study of marine materials (especially those serving in harsh marine environment) have remarkable novelty.

5.3.3. Erosion Mechanism of Ship Materials in Polar and Open Sea Environments. Study the corrosion resistance, abrasion resistance, crack arrest, welding repair, and coating performance of steel used for arctic icebreakers in a special environments. Establish the testing standards, laying a foundation for the quantification and theoretical study of abrasion phenomenon. Study the key problems in the design of ships sailing in the ice region. Study the spatial distribution characteristics and the determination method of ice load. Study the ultimate bearing capacity of ship hull structure in ice region. Combined with these, the study of marine harsh environment materials can be condensed into three important research directions which are interrelated and characteristic.

\section{Conclusion}

In this paper, based on the data accumulation and shortcomings of the study on the mechanism of corrosion of deep-sea environmental materials, the establishment of the deep-sea hydrothermal zone environmental materials research platform is proposed to promote the improvement of the theoretical study of deep-sea material corrosion and the research and development of adaptive materials. On this basis, the research scope of deep-sea material corrosion 
mechanism is extended to the high humidity and heat of the South China Sea, the research and development of equipment and materials for ocean transportation and marine transportation, and the research and development of corrosion protection technology for ship engineering materials in polar environments.

\section{Data Availability}

The data used to support the findings of this study are available from the corresponding author upon request.

\section{Conflicts of Interest}

The authors declare that there are no conflicts of interest regarding the publication of this paper.

\section{Acknowledgments}

This work was funded by Zhejiang Provincial Key Research and Development Program, Grant/Award Number: 2021C03013; Fundamental Research Funds for the Provincial Universities of Zhejiang, Grant/Award Number: GK199900299012-026; National Natural Science Foundation of China, Grant/Award Number: 42006167; and Natural Science Foundation of Zhejiang Province, Grant/Award Numbers: LQ19D060008 and LZ21E050002.

\section{References}

[1] C. R. German and K. L. Von Damm, "Hydrothermal processes," Treatise on geochemistry, vol. 6, p. 625, 2003.

[2] W. Guo, M. Sun, Ri Qiu, and X. Li, "Research progress on corrosion and aging of materials in deep-sea environment," Corrosion Science and Protection Technology, vol. 29, no. 3, pp. 313-317, 2017.

[3] W. M. Guo, W. Li, and G. Z. Chen, "Corrosion testing in the deep ocean," Equipment Environment Enquiring, vol. 3, no. 1, pp. 10-15, 2006.

[4] M. Schumacher, Seawater Corrosion Handbook, Noyes data corporation, Park Ridge, New Jersey, USA, 1979.

[5] L. K. Xu, W. J. Li, and G. Z. Chen, "Deep sea corrosion test technique," Marine Sciences, vol. 29, no. 7, pp. 1-3, 2005.

[6] I. Ulanovskii and V. Egorova, "Metal corrosion at different depths in the sea," Proteus, vol. 14, pp. 137-139, 1978.

[7] I. Ulanovskii, "Corrosion of metals in the Atlantic Ocean," Proteus, vol. 15, pp. 563-566, 1979.

[8] S. S. Sawant, K. Venkat, and A. B. Wagh, "Corrosion of metals and alloys in the coastal and deep waters of the Arabian Sea and the Bay of Bengal," Indian Journal of Technology, vol. 31, no. 12 , pp. 862-866, 1993.

[9] S. S. Sawant and A. B. Wagh, "Corrosion behaviour of metals and alloys in the waters of the Arabian Sea," Corrosion Prevention and Control, vol. 36, pp. 154-157, 1990.

[10] C. Wang, H. Wu, and H. Y. Yang, "Electrochemical behavior of organic coatings in simulated deep ocean environment," Corrosion Science and protection Technology, vol. 21, no. 4, pp. 351-353, 2009.

[11] P. Traverso and E. Canepa, "A review of studies on corrosion of metals and alloys in deep-sea environment," Ocean Engineering, vol. 87, no. 1, pp. 10-15, 2014.
[12] E. Canepa, R. Stifanese, L. Merotto, and P. Traverso, "Corrosion behaviour of aluminium alloys in deep-sea environment: a review and the KM3NeT test results," Marine Structures, vol. 59, pp. 271-284, 2018.

[13] B. J. Little and J. S. Lee, "Microbiologically influenced corrosion: an update," International Materials Reviews, vol. 59, no. 7, pp. 384-393, 2014.

[14] G. Luciano, P. Letardi, and P. Traverso, "Corrosion behavior of $\mathrm{Al}, \mathrm{Cu}$, and Fe alloys in deep sea environment," La Metallurgia Italiana, vol. 105, no. 1, pp. 21-29, 2013.

[15] J. Hou, W. Guo, and C. Deng, "Influences of deep sea environmental factors on corrosion behavior of carbon steel," Equipment environment engineering, vol. 5, no. 6, pp. 85-87+104, 2008.

[16] W. Peng, J. Hou, and W. Guo, "Research progress on the corrosion of Aluminum Alloy in deep ocean," Development and Application of Materials, vol. 25, no. 1, pp. 59-62, 2010.

[17] J. Liu, X. Li, and J. Wang, "EIS characteristic of organic coating with artificial defects in simulated deep-sea environment," Corrosion Science and Protection Technology, vol. 22, no. 4, pp. 333-337, 2010.

[18] J. Zhou, X. Li, X. Cheng, and C. Dong, "Research progress on corrosion of metallic materials in deep sea environment," Corrosion Science and Protection Technology, vol. 22, no. 1, pp. 47-51, 2010.

[19] J. Chen, X. Jiang, Ze Zhang, and Yi Wang, "Review on environmental influence factors of submarine optical fiber cable," Electronic product reliability and environmental testing, vol. 36, no. S1, pp. 242-246, 2018.

[20] J. Liu, X. Li, and J. Wang, "Effect of hydrostatic pressure on the corrosion behaviors of two low alloy steels," Acta Metallurgica Sinica, vol. 6, pp. 697-705, 2011.

[21] H. Sun, Li Liu, and Li Ying, "Corrosion behavior of a high strength low alloy steel under hydrostatic pressure in deep ocean," Journal of Electrochemistry, vol. 19, no. 5, pp. 418-424, 2013.

[22] Y. Yang, T. Zhang, Y. Shao, and G. Meng, "Effect of hydrostatic pressure on the corrosion behavior of Ni-Cr-Mo- $\mathrm{V}$ high strength steel," Corrosion Science, vol. 52, no. 8, pp. 2697-2706, 2010.

[23] P. Pohjanne, "Effect of deep sea environment on corrosion of some aluminum alloys," Finland VTT Offsetpaino: Espoo Research Reports, vol. 724, p. 17, 1991.

[24] W. Guo, C. Deng, and W. Li, "Testing method and apparatus for deep sea corrosion potential of metallic materials," CN101074917, 2007.

[25] L. I. Qiang and L. I. Yan, “A design of watertight electronic cabin for in-situ electrochemical measurement under deep sea condition," Marine Science, vol. 37, no. 11, pp. 64-68, 2013.

[26] W. Wang, W. Guo, and H. Zhang, "Research on the corrosion of stainless steel in deep sea," Equipment Environmental Engineering, vol. 7, no. 5, pp. 79-83, 2010.

[27] W. Yuan, Effect of marine Service Environment on Electrochemical Corrosion Behavior and Hydrogen Embrittlement under Cathodic protection of X80 Steel, Wuhan University of Science and Technology, Wuhan, China, 2020.

[28] Y. Huang, C. Cao, and H. Lin, "Investigation on SCC and SCCinhibition of AISI 316L stainless steel in acidic chloride solution," Corrosion Science and Protection Technology, vol. 5, no. 3, pp. 192-196, 1993.

[29] B. Liu, "Study on the evaluation technique for the performance of anticorrosion coatings under deep sea environment," Shanghai Coatings, vol. 49, no. 5, pp. 34-36, 2011. 
[30] J. Wang, J. Meng, X. Tang, and W. Zhang, "Assessment of corrosion behavior of steel in deep ocean," Journal of Chinese Society for Corrosion and Protection, vol. 27, no. 1, pp. 1-7, 2007.

[31] L. K. Xu, Material Failure and protection in Ocean Engineering, Chemical Industry Press, Beijing, 2014.

[32] R. Venkatesan, Studies on Corrosion of Some Structural Materials in Deep Sea Environment, India Department of Metallurgy India Institute of Science, Bengaluru, 2000.

[33] X. Tang, J. Wang, and Li Yan, "Effect of flow velocity of seawater on corrosion rate for A3 steel," Marine Science, vol. 7, pp. 26-29, 2005.

[34] Y. Wang, "Corrosion behavior of aluminum alloy in flowing seawater," Equipment environmental Engineering, vol. 2, no. 6, pp. 72-78, 2005.

[35] K. Ding, L. Fan, and W. Guo, "Deep sea corrosion behavior of typical metal materials and research hotspot discussion," Equipment environmental engineering, vol. 16, no. 1, pp. 107-113, 2019.

[36] Z. Cui, S. Chen, Y. Dou et al., "Passivation behavior and surface chemistry of 2507 super duplex stainless steel in artificial seawater:Influence of dissolved oxygen and $\mathrm{pH}$," Corrosion Science, vol. 150, pp. 218-234, 2019. 